\title{
Retraction Note: Dual-time point positron emission tomography findings of benign mediastinal lymph nodes in a tuberculosis-endemic region
}

\author{
Dae-Weung Kim • Chang Guhn Kim
}

Published online: 15 September 2012

(C) Japan Radiological Society 2012

Retraction to: Jpn J Radiol (2011) 29:682-687

DOI 10.1007/s11604-011-0613-7

The article "Dual-time point positron emission tomography findings of benign mediastinal lymph nodes in a tuberculosis-endemic region", Japanese Journal of Radiology [doi 10.1007/s11604-011-0613-7] is retracted due to prior publication.

The online version of the original article can be found under doi:10.1007/s11604-011-0613-7.

D.-W. Kim · C. G. Kim ( $($ )

Department of Nuclear Medicine and Institute of Wonkwang

Medical Science, Wonkwang University School of Medicine,

344-2 Shinyong-Dong, Iksan, Jeollabuk-do 570-711,

Republic of Korea

e-mail: akaxan@naver.com 